\title{
Motivos de fusiones y grupos económicos: El caso Davivienda - Bansuperior - Bancafé
}

\author{
Ingrid Suárez, Yuri Gorbaneff, Jorge Beltrán / yurigor@javeriana.edu.co \\ Departamento de Administración, Facultad de Ciencias Económicas \\ y Administrativas, Pontificia Universidad Javeriana
}

\section{RESUMEN}

El artículo propone una agrupación de los motivos de fusiones por corrientes teóricas y determina la aplicabilidad de los mismos en el caso de la fusión Davivienda - Bansuperior - Bancafé. El marco teórico recopila 17 tipologías de motivos de fusiones y es guiado por tres corrientes teóricas: economías de escala y alcance, costos de transacción y enfoque basado en recursos y capacidades. El método utilizado fue el estudio de caso, cuya información fue obtenida de diversas fuentes secundarias y entrevistas a profundidad realizadas a altos directivos. Se utilizó la escala de Likert para la clasificación de actitudes. En el caso fueron comprobados algunos motivos reseñados en la literatura. También se encontró que un motivo para la fusión horizontal de una empresa, que pertenece a un grupo empresarial, es la obtención de beneficios para las demás empresas del grupo, a través del ahorro en costos de transacción derivado de los enlaces verticales, que se generan entre las demás empresas pertenecientes al grupo y la empresa fusionada. El peso específico de los motivos verticales en una fusión eminentemente horizontal, exige una futura investigación.

Palabras clave: Bancos, tipologías de motivos, fusión horizontal, costos de transacción

\section{ABSTRACT}

The article studies the motives for mergers. It groups them according to their theoretical roots and shows their usefulness in the case of the merger of Colombian banks Davivienda - Bansuperior - Bancafé. The theoretical frame compiles 17 typologies of motives for merger grouped into three blocks: scale and scope economies, transaction costs and resource based approach. We used the case study method. We obtained data from interviews with Davivienda executives and secondary sources. We used the Likert scale to capture the attitudes of the respondents. We found in the case the majority of motives studied in the literature. One new motive was identified. Particularly one motive for a horizontal merger of Davivienda was the transaction costs economizing by other firms of the economic group to which belongs Davivienda. The specific weight of the transaction costs vertical motives in an essentially horizontal merger deserves further research.

Key words: Banks, typologies of motives for merger, horizontal merger, transaction costs 


\section{INTRODUCCIÓN}

Después de una subasta pública de acciones realizada el 12 de octubre de 2006, con el fin de adjudicar el 99,06\% del Granbanco - Bancafé, y con ello, privatizar uno de los más grandes bancos del país; Davivienda, banco perteneciente al Grupo Bolívar, uno de los principales grupos financieros del país, le ganó la puja al Grupo Aval, segundo conglomerado financiero del país, ofreciendo 2.21 billones de pesos por el banco estatal (La República, 2006c; Revista Dinero, 2007). Así, Davivienda se convirtió en el tercer banco más grande del país, después de Bancolombia (primero) y Banco de Bogotá (segundo). La fusión Davivienda - Granbanco - Bancafé fue una estrategia para competir con los nuevos integrantes del sector bancario, entre los que figuran gigantes como el HSBC y el General Electric Money. Cabe resaltar que la fusión con Bansuperior, que precedió a la de Granbanco - Bancafé, le permitió a Davivienda adquirir experiencia en fusiones y evitar errores cometidos en el pasado. Bansuperior poseía la franquicia de la tarjeta de crédito Dinners para Colombia, con unas utilidades de aproximadamente 30.000 millones 51 anuales y alrededor de 1.000 personas empleadas. Davivienda advirtió oportunamente que obtenía, en menor tiempo y a menores costos, acceso a un activo que incluía cerca de un millón de clientes adicionales, que habían sido conseguidos tras cuarenta años y recibían un trato similar al de socios.

La fusión de Davivienda con Banco Superior (2005) y Bancafé (2006) avivó el interés por las fusiones y adquisiciones en el país, y, en especial, por los motivos de esta estrategia empresarial. El tema de los motivos de las fusiones está insuficientemente explorado en la literatura internacional y mucho menos en la colombiana. Se sabe que las fusiones y adquisiciones, en la mayoría de los casos, fracasan en el cumplimiento de sus objetivos iníciales declarados (McCann y Gilkey, 1990). Este hecho indica que nuestra comprensión de los motivos de las fusiones requiere mayor profundidad. Efectivamente, en la literatura, no existe un consenso acerca de los motivos de las fusiones. Se encuentran numerosas tipologías que varían en la gama de motivos identificados, en el grado de detalle de su descripción y en los enfoques teóricos. Ninguna tipología establece una diferen- 
ciación entre los motivos de tipo horizontal y los de tipo vertical para una fusión. Tampoco proveen pruebas de su aplicabilidad.

El objetivo del presente trabajo es explorar las tipologías existentes de motivos de fusiones y evaluar su aplicabilidad para el caso de la reciente fusión de Davivienda - Bansuperior (2005) - Bancafé (2006). La fusión mencionada reviste importancia por varias razones. En un primer momento, es un caso representativo del sistema financiero colombiano, cuyos bancos, por lo general, no actúan solos sino que forman parte de grupos económicos. En un segundo momento, a pesar de haber sido una operación que reconfiguró el sistema financiero colombiano porque transformó a Davivienda en el primer banco hipotecario y de consumo y en el segundo banco comercial del país, existe aún escasa información sobre la transacción. En un tercer momento, se trata de una fusión que involucra un banco estatal que estaba en proceso de privatización.

Aunque los motivos de las fusiones son un tema de debate constante en el ámbito científico internacional, en la literatura colombiana no se encontraron estudios que trataran la problemática de los motivos de las fusiones ni el caso de Davivienda. Por tal razón, este trabajo pretende contribuir a la literatura internacional y colombiana sobre los motivos de las fusiones.

El documento tiene carácter descriptivo y analítico, que combina las técnicas de estudio documental y de estudio de caso. En cuanto sigue, el trabajo se divide en 3 secciones. La primera, presenta el resumen de la literatura sobre las fusiones. La segunda sección describe el caso de Davivienda. La tercera, presenta la discusión de los hallazgos. La cuarta, concluye.

\section{LITERATURA}

El tema de las fusiones se aborda, en la literatura, desde tres perspectivas: la teoría económica clásica, concretamente, la organización industrial; la teoría de los costos de transacción, y el direccionamiento estratégico. Según la teoría económica clásica, las fusiones buscan lograr economías de escala y economías de alcance (Besanko, Dranove, Shanley, 1996). Un proceso de producción exhibe economías de escala cuando el costo promedio por unidad de producción cae, 
mientras el volumen de producción se incrementa. Existen economías de alcance siempre que una firma ahorra al incrementar la variedad de los bienes que produce.

Besanko, Dranove, \& Shanley (1996, p. 174) definen economías de escala como el declive del costo promedio (costo por unidad de producción) al sobrepasar un rango de producción. De modo que: “...para que el costo promedio (CP) decline con el incremento de la producción, el costo marginal (CM) o costo de la última unidad producida, debe ser menor que el costo promedio total". Entonces cuando el costo marginal es menor al costo promedio, existen economías de escala. Si sucede lo contrario, es decir, que el costo marginal es mayor que el costo promedio se dice que hay retornos decrecientes de escala. También puede suceder que el costo promedio sea igual al costo marginal, caso en el cual se tendrían retornos constantes a escala, es decir que, aun cuando aumente la producción sobre un rango, los retornos serán los mismos.

Los teóricos de los costos de transacción explican las fusiones por el deseo de ahorrar los costos de transacción que se dan en una relación vertical, o simbiótica (Jones, 2008). La fusión (integración) vertical permite a la firma coordinar diversos factores de producción sin la intervención del mecanismo de precios (Besanko, Dranove, y Shanley, 1996, p. 93; Coase, 1937; Williamson, 1996, p. 41). Coase (1937) describió la firma como el sistema de relaciones que existen cuando la dirección de los recursos depende de una sola persona: el empresario. Su tamaño se define en relación con el número de transacciones que realice; se expande si adquiere transacciones adicionales, y se reduce mientras menor sea el número de dichas transacciones organizadas por el empresario bajo una misma firma. Algunos costos de transacción son: el tiempo y expensas que se gastan en la negociación, escritura y puesta en marcha de los contratos, los perjuicios del comportamiento oportunista que puede presentarse por una o ambas partes y los costos de intentar prevenirlo (Besanko, Dranove, \& Shanley, 1996, p. 93).

La dirección estratégica explica las fusiones dentro del enfoque de recursos, como la lucha de las organizaciones por el control de los recursos a fin de minimizar su dependencia del entorno (Daft, 2000, pp. 99, 527; Wernerfelt, 1997, pp. 122-127). De manera concreta, las empresas buscan, a través de las fusiones, incrementar la cuota de 
mercado (Besanko, Dranove, y Shanley, 1996, p. 206) y el poder de mercado (Tirole, 2002, p. 284). Entender una fusión desde el direccionamiento estratégico debe incluir la comprensión del papel que jugará la fusión o adquisición en el futuro de la empresa, el análisis y entendimiento de la posición actual de la compañía y la deseada y por último, requiere que se planee deliberadamente el proceso estratégico y se desarrolle con miras a alcanzar el objetivo deseado.

Existen numerosas tipologías de fusiones. Un estudio realizado por Depamphilis (2005) da cuenta de nueve motivos. La sinergia operativa es el primero y consiste en mejorar la eficiencia de las operaciones a través de economías de escala y alcance. El segundo es la sinergia financiera, que se refiere a la reducción en el costo de capital como resultado de flujos de caja más estables, economías financieras de escala, o mejores oportunidades de inversión con los fondos disponibles. La diversificación es el tercero; ocurre cuando se compran firmas fuera de la línea de negocios primaria de la compañía en productos o mercados con altos niveles de crecimiento; puede darse con nuevos productos en los mercados actuales, nuevos productos y nuevos mercados o los productos actuales en nuevos mercados. El cuarto motivo señalado por Depamphilis (2005) es el realineamiento estratégico, en el que la fusión surge como un mecanismo para un ajuste rápido a los cambios en el entorno externo, como pueden ser los casos de una desregulación o innovación tecnológica. La arrogancia es el quinto motivo y se presenta como una explicación para adquisiciones que tienen la tendencia de pagar demasiado, debido a un excesivo optimismo del valor de la sinergia potencial de un negocio o la excesiva confianza en las habilidades de la administración para manejar la adquisición.

Otro motivo es la subvaloración de recursos, que considera que el valor de mercado de un negocio es menor que el valor de reemplazo de sus recursos. La mala administración o teoría de la agencia figura también como un motivo que se presenta cuando existen diferencias entre lo que quieren los gerentes y lo que quieren los accionistas. Los bajos precios de las acciones de una firma constituyen un factor de presión para que los gerentes tomen medidas orientadas a subir el precio de la acción o para que se conviertan en el objetivo de un adquiriente. El poder de mercado es el octavo 
motivo, y considera que las firmas se fusionan para tener más control sobre la fijación de precios. Conviene, no obstante, destacar que el soporte empírico para esta noción es limitado. El noveno y último motivo lo ofrece la teoría administrativa, según la cual los gerentes adquieren compañías para incrementar el tamaño del adquiriente y su propia remuneración. Los motivos de una actividad de fusión o adquisición para compañías en expansión, suelen ser el deseo de alcanzar economías de escala y alcance, penetrar nuevos mercados, acceder a diseños nuevos, tecnología, procesos de producción y sinergias benéficas para ambas firmas. En contraste, para compañías en declive, la fusión puede ser motivada por el deseo de resucitar la firma y prevenir así un deterioro futuro (Vermeulen y Barkema, 2001, citado por Donnelly, Morris, \& Donnelly, 2005). Las "teorías gerenciales" argumentan que las fusiones se ven motivadas cuando el crecimiento de la firma es el objetivo principal de los gerentes de turno más que la rentabilidad de la misma, dado que les otorga mayor estatus y remuneración (Vermeulen y Barkema, 2001; Seth et al., 2000 pp. 2-3, citados por Donnelly, Morris, \& Donnelly, 2005). En el estudio de caso sobre las fusiones en un país en desarrollo como es Malasia, Shanmugam y Nair (2004) encontraron que éstas obedecen a factores como la globalización, la liberalización y el desarrollo de la tecnología de la información, los cuales contribuyen a la necesidad de sistemas financieros más competitivos y fuertes. Un factor igualmente ponderable lo constituyen las crisis económicas; de hecho, la crisis financiera asiática de 1997 ocasionó una ola de fusiones bancarias en Malasia, reduciendo el número de bancos de 54 a 10 más fuertes (Shanmugam \& Nair, 2004). Gaughan (2002) considera que la obtención de sinergias es el motivo más importante para realizar una fusión. La sinergia es la habilidad para lograr que una combinación corporativa resulte más rentable que la suma de las firmas involucradas. Las sinergias pueden ser operativas y financieras. Las primeras permiten incrementar los ingresos y reducir costos; las segundas disminuyen el costo de capital (Gaughan, 2002, pp. 111-161). El incremento en los ingresos se puede obtener de la creación de un producto o servicio más fuerte. La reducción en costos puede ser el resultado de economías de escala y alcance (Gaughan, 2002, pp. 118-119). Las sinergias financieras se obtienen con la disminución en 
los costos de capital de la firma adquiriente o de los socios en conjunto. Una firma más grande disfruta de mejor acceso a los mercados financieros, pues se considera que implica menor riesgo y comporta ciertas ventajas que permiten un menor costo de capital (Gaughan, 2002, pp. 121-123).

Las fusiones permiten crecer y expandirse a un ritmo más rápido y con menores riesgos, acceder a recursos claves, apoderarse de una porción de mercado, aprovechar una ventana de oportunidad, construir ventajas competitivas, expandirse geográficamente e incrementar utilidades. La diversificación es la expansión de una compañía fuera de su categoría de industria actual, a través de la obtención de posiciones privilegiadas en una industria, la entrada en una más rentable, la reducción del riesgo y la volatilidad de las ventas (Gaughan, 2002, pp. 123-129). Este autor incluye el poder de mercado y la integración vertical dentro de una categoría que denomina motivos económicos. El poder de mercado es la habilidad de fijar y mantener un precio por encima del costo marginal. Los motivos personales de los directivos, como la hipótesis de la arrogancia, también pesan a la hora de la fusión. La hipótesis de la arrogancia es un motivo personal basado en los sentimientos como la arrogancia u orgullo de los gerentes. Este motivo se evidencia cuando el precio de la acción de la firma adquiriente cae y el de la adquirida aumenta, como resultado del exceso de prima pagada (Roll, R, 1986 citado por Gaughan, 2002, p. 147). La compensación ejecutiva, por su parte, describe la situación en que la pretensión de mejores compensaciones y beneficios puede motivar a los gerentes a realizar una fusión que expanda la compañía. Sin embargo, es necesario anotar que sólo las buenas operaciones lo permiten (Gaughan, 2002, pp. 150-151). Por último, se encuentran los motivos tributarios y otros, entre los que se incluyen la introducción de mejoras en la administración, investigación y distribución. La importancia de los motivos tributarios, que se refieren al ahorro en impuestos que se logra con una fusión, ha sido debatida constantemente; ello no ha impedido, sin embargo, que se la continúe citando como un motivo (Gaughan, 2002, pp. 154-158). En cuanto al propósito de mejorar la administración, éste tiene que ver con la creencia en las habilidades de administración superiores de la firma adquiriente, que se supone permitirán incrementar el 
valor de la firma adquirida. Tiene mayor validez cuando una compañía grande compra una pequeña que posee gran potencial (Gaughan, 2002, p.151). La motivación de mejorar la investigación y el desarrollo, posibilita el crecimiento a largo plazo de las empresas, sobre todo de aquellas que dependen en mayor grado de estos aspectos, como las farmacéuticas (Gaughan, 2002, pp. 151-152). Finalmente, el motivo de mejorar la distribución opera cuando la fusión se realiza para acceder directamente a los consumidores, maniobra que posibilita el desarrollo de canales más rentables (Gaughan, 2002, pp. 153-154). Un estudio realizado sobre fusiones de bancos italianos entre 1985 y 1996, mostró que éstas se realizaban en atención a incrementar el alcance de los servicios del banco activo (Focarelli, Panetta, \& Salleo, 2002, pp.12-19). En este punto se estaría hablando de economías de alcance.

Mascareñas (2000) estudia los motivos de fusiones desde el punto de vista económico y procura determinar si logran su objetivo de maximizar el valor de la empresa. La sinergia se logra cuando el valor de mercado de las empresas combinadas es mayor que la suma de sus valores independientes. En las fusiones se paga una prima, dado que el valor de una firma que va a fusionarse aumenta. La sinergia esperada debe superar el valor conjunto de la prima pagada más los costos de hacer la transacción (Mascareñas, 2000, pp. 2-3). Los motivos que se reseñan a continuación son los que Mascareñas (2000) considera que producen sinergias. La integración horizontal permite obtener sinergias operativas, a través del aumento de los ingresos o la reducción de los costos (Mascareñas, 2000, p. 5). El aumento de los ingresos se obtiene por la creación de un nuevo producto o servicio, gracias al intercambio de oportunidades de marketing, reputación e imagen de marca (Mascareñas, 2000, p. 6). La reducción en costos es la consecuencia del aumento en el volumen de producción y de la especialización del personal. En las fusiones bancarias se generan economías de alcance al expandir sus productos o servicios con los mismos costos (Mascareñas, 2000, pp. 6-7). El poder de mercado es la posibilidad de establecer y mantener un precio superior al de la competencia. Puede obtenerse a través de la diferenciación de productos, la colocación de barreras de entrada y la ampliación de la cuota de mercado. Las fusiones horizontales generan mayor concentración del sector, obligando a crear leyes antimonopolio (Mascareñas, 2000, pp. 7-8). 
Las integración vertical facilita un mayor acercamiento al consumidor final o la fuente de materia prima porque permite reducir los costos de transacción, de comunicación y coordinación (Mascareñas, 2000, p. 9). Es, además, posible obtener una mejoría en los rendimientos a través de la fusión, con la eliminación de una gestión ineficiente (Mascareñas, 2000, pp. 10-11). En ocasiones, existen ventajas fiscales que no han sido aprovechadas y que podrían reducir el pago de impuestos. La carga fiscal de las compañías unidas es menor que la que tendrían que pagar por separado. No obstante, para la ponderación precisa de este aspecto, se debe tener en cuenta la legislación de cada país (Mascareñas, 2000, pp. 11-12). Hay asimismo un conjunto de motivos que son criticados por el autor por considerar que crean valor para los directivos, si bien no siempre para los accionistas. Se trata de los siguientes: La fusión como diversificación del riesgo, que describe la situación en la cual se crean conglomerados que reducen el riesgo económico de la empresa sin crear el valor para los accionistas (Mascareñas, 2000, pp. 15-17). Otra situación descrita es cuando los directivos de grandes empresas quieren extender su control a un mayor número de empleados, aumentar el volumen de ventas y los activos de la empresa. En este caso, los directivos persiguen sus objetivos personales antes que los de los accionistas (Mascareñas, 2000, pp. 18-19). El orgullo arrogante de los directivos los lleva a considerar el mercado como ineficiente y a adquirir empresas para cumplir sus objetivos personales. La fusión crea riqueza en relación con los beneficios por acción y otorga mayores facilidades crediticias, capacidad de endeudamiento y liquidez (Mascareñas, 2000, pp. 21-24).

En algunos casos, la fusión permite alcanzar la tasa deseada de crecimiento a un costo menor que el del crecimiento interno (Mascareñas, 2000, p. 24). En otros, la fusión permite adquirir activos importantes a muy bajo costo, situación que se presenta cuando se tiene acceso a información privilegiada acerca del valor de la compañía, en este caso sub valorada por el mercado, y de la administración ineficiente de sus activos (Mascareñas, 2000, pp. 24-25). Las fusiones permiten crecer y aumentar el valor del grupo, siendo más costoso para un adquiriente hostil adquirir el control de la empresa (Mascareñas, 2000, p. 26). El movimiento defensivo se da cuando una compañía adquiere a un competidor para reducir la competencia (Mascareñas, 
2000, p. 26). La búsqueda del protagonismo también motiva a los directivos a realizar una fusión (Mascareñas, 2000, pp. 27-28).

Fröhlich \& Kavan (2000) ofrecen un análisis de los motivos de fusiones y adquisiciones bancarias realizadas en el período de 19961997 en EE.UU., en el cual identifican cuatro motivos principales. El primero de ellos es crear economías de escala que se obtiene gracias a la combinación de las dos organizaciones. El segundo es la expansión geográfica de mercados que permite disminuir el riesgo total y aumentar las ventas. El tercero es la economía de alcance que puede surgir al incrementar la cantidad de productos ofrecidos. El cuarto es obtener poder de mercado.

Para Ballarín, Canals \& Fernández (1994), existen cuatro motivos que explican las fusiones y adquisiciones. El primero es la búsqueda de sinergias que pueden orientarse a tres propósitos: la reducción de ineficiencias (se producen cuando la empresa tiene productividad o rendimientos inferiores a otra empresa del mismo sector con características similares), la obtención de sinergias operativas (alcanzar economías de escala, alcance y poder de mercado), y de sinergias financieras (reducción del costo de capital, desarrollo de un mercado de capitales interno de la empresa o menor costo de las emisiones de deuda) (Ballarín, Canals, \& Fernández, 1994, pp.11-18). El segundo motivo es la diversificación que permite reducir la dependencia del mercado de capital mediante la creación de uno interno, incrementar la capacidad de negociación con las entidades financieras, disminuyendo los costos financieros, adquirir activos intangibles y aprovechar la fuerza de la marca propia en otros negocios (Ballarín, Canals, \& Fernández, 1994, p. 47). El tercer motivo hace referencia a problemas de la agencia y guarda la relación con la finalidad de disciplinar a la gerencia. Los problemas de la agencia se refieren al desequilibro entre la voluntad de los accionistas y de los directivos (Ballarín, Canals, \& Fernández, 1994, pp. 39 - 55). Sin embargo, algunos autores argumentan que se trata de un motivo que no es válido, pues la competencia en el mercado final se encarga de disciplinar a los gerentes (Jensen y Meckling, 1976; Alchian y Woodward, 1987, 1988, citados por Ballarín, Canals \& Fernández, 1994, p. 51). El cuarto y último motivo, denominado exceso de recursos generados, tiene lugar cuando los directivos prefieren retener las utilidades, en lugar de 
repartirlas en dividendos, con el fin de reducir su dependencia del mercado externo e incrementar su poder (Jensen, 1986, citado por Ballarín, Canals, \& Fernández, 1994, p. 52). Entonces, los accionistas realizan una fusión o adquisición por la necesidad de disciplinar la actuación de los equipos directivos y al mismo tiempo motivar la eficiencia de la firma, a través del incremento del endeudamiento de la empresa (Grossman y Hart, 1980, citado por Ballarín, Canals, \& Fernández, 1994, p. 52). Ballarín, Canals, \& Fernández (1994, p. 54) aclaran que varios autores están en desacuerdo con el último motivo, porque consideran que las fusiones son proyectos atractivos para invertir los excedentes, y que no siempre los directivos buscan poder. La acumulación responsable de recursos a largo plazo puede ser benéfica, cuando se destinan para desarrollo de nuevas tecnologías o adquisición de empresas.

El estudio de Schein y otros (1990, p.10) plantea que, paralelamente con los motivos explícitos, existen motivos tácitos que pueden incluir necesidades de poder personal, crecimiento y expansión de la identidad, destrucción o sometimiento de otras organizaciones, y necesidad de reducir el poder del sindicato.

McCann \& Gilkey (1990) realizan una categorización que incluye ocho motivos. El primero es la "caja ociosa”. Ocurre cuando las empresas no encuentran otro uso para sus ganancias. El segundo motivo es la reducción de riesgos y la diversificación, por medio de la adquisición de empresas en otro sector económico (McCann \& Gilkey, 1990, pp. 25-26). El tercer motivo es fortalecerse frente a la competencia. En este caso la organización reacciona a un factor externo en vez de adoptar una actitud proactiva de largo plazo (McCann \& Gilkey, 1990, pp. 26-27). El cuarto motivo es la percepción de activos infrautilizados o infravalorados, que se observa principalmente en las adquisiciones hostiles. El quinto motivo es el logro de las sinergias. Por ejemplo, los activos sub utilizados pueden tener un mejor uso después de la fusión; un equipo de ventas puede vender los productos de ambas empresas; la capacidad de la planta de una empresa puede ser utilizada para fabricar productos de otra empresa; a veces es posible usar las innovaciones tecnológicas de una empresa para mejorar los productos de otra; se obtienen sinergias de recursos humanos, al administrar talentos en lugar de robarlos (McCann \& Gilkey, 1990, pp. 
28-29). Los beneficios legales y fiscales son el sexto motivo para una fusión. No obstante, McCann \& Gilkey (1990, p. 29) consideran que el actual seguimiento de los organismos gubernamentales hacen difícil obtener estos beneficios. Como séptimo motivo figura el acceso a nuevas tecnologías y procesos (McCann \& Gilkey, 1990, p. 30). El último motivo son las consideraciones egocéntricas que, aunque siempre operan tácitamente en las fusiones, nunca se hacen explícitas.

Para Pfeffer (1972) las fusiones se realizan con el objeto de absorber la interdependencia simbiótica o la interdependencia competitiva. La fusión se realiza para diversificarse, su motivo será evadir las interdependencias existentes, al reducirlas por medio de la diversificación de las actividades de la organización.

Felton (1971, pp. 229-230) considera que los motivos de las fusiones se enmarcan en las ventajas privadas que se obtienen del crecimiento externo de la firma sobre el interno. Entre tales ventajas figura la posesión de recursos valiosos de una empresa existente, como el good will.

En su estudio de motivos de fusiones, Trautwein (1990) analiza la solidez empírica y teórica de los siete motivos de fusiones más comunes en la literatura. La teoría de la eficiencia, que incluye varios tipos de sinergias, es criticada por contradecir la lógica del mercado de capitales (Kitching, 1967; Porter, 1987, citados por Trautwein, 1990, p.288). Las sinergias operativas y gerenciales no motivan las fusiones (Kitching, 1967; Porter, 1987, citado por Trautwein, p. 288). Las fusiones y adquisiciones son un mecanismo disciplinante del control corporativo para los gerentes que no maximizan el valor de los accionistas. Con la fusión, el control interno ineficiente de los accionistas es reemplazado por un control externo eficiente basado en la competencia con otros grupos de gerentes. Según la teoría del monopolio, las fusiones se realizan para obtener poder de mercado y bloquear la entrada de competidores. Trautwein (1990, p. 288) comparte este motivo y considera que este motivo generalmente es enmascarado como búsqueda de eficiencia o expansión del mercado objetivo. El autor no encuentra soporte empírico para la teoría del invasor, según la cual la organización adquiriente paga una prima por controlar las acciones de la compañía adquirida (Trautwein, 1990, p. 291 - 292). El autor apoya la teoría de la valuación que se 
refiere a las ganancias netas que resultan de la información privada (Trautwein, 1990, p. 288 - 289). También existe la evidencia a favor de la teoría de la construcción del imperio (Trautwein, 1990, 289290). La teoría del proceso entiende las fusiones como decisiones estratégicas incomprensibles racionalmente, pues son el resultado de procesos guiados por información limitada, rutinas organizacionales y poder político. Aunque no encuentra la evidencia a favor de esta teoría, Trautwein (1990, p.289-290) explica que en algunos estudios de caso, los asuntos políticos, estructurales o diferencias culturales ejercen una gran influencia. La teoría de la perturbación explica las fusiones como el resultado de perturbaciones económicas que alteran las expectativas individuales e incrementan la incertidumbre (Gort, 1969, citado por Trautwein, 1990, pp. 292-293). Para Trautwein (1990, pp. 292-293), no puede generalizarse la relación entre las crisis económicas y las olas de fusiones, puesto que no siempre se relacionan. Por ejemplo, las crisis suelen ser sectoriales y las olas no siempre lo son. El autor encuentra la evidencia a favor de la teoría de la interdependencia organizacional debido a un entorno incierto e inestable en el cual las organizaciones necesitan reducir la incertidumbre (Green \& Cromley, 1982).

Finalmente, el resumen de la literatura sería incompleto sin mencionar las publicaciones colombianas. En lo que respecta al ámbito nacional, los estudios académicos no se centran en el análisis de las motivaciones de las fusiones. El informe de la ANIF (2006) estudia la consolidación bancaria desde 1990 - 2006 en la configuración del sistema financiero. La crisis financiera de 1998-1999, ocasionó 89 liquidaciones en todo el sector financiero. A partir del 2003 se viene gestando un proceso de recuperación a partir de fusiones bancarias. En este sentido, el trasfondo histórico de las fusiones es una mayor consolidación bancaria que crea las entidades más grandes y diversificadas, pero sin serias amenazas a la estructura competitiva del sector bancario. Así, las fusiones han logrado explotar diferentes sinergias y han diversificado la cartera de los bancos. Por otra parte, el estudio de Urdaneta (2008) examina el cambio del modelo de administración de los bancos de inversión colombianos, y el estudio de Berggrun (2006) analiza la fusión de Bancolombia, Conavi y Corfinsura desde el punto de vista de la creación de valor para los accionistas. 


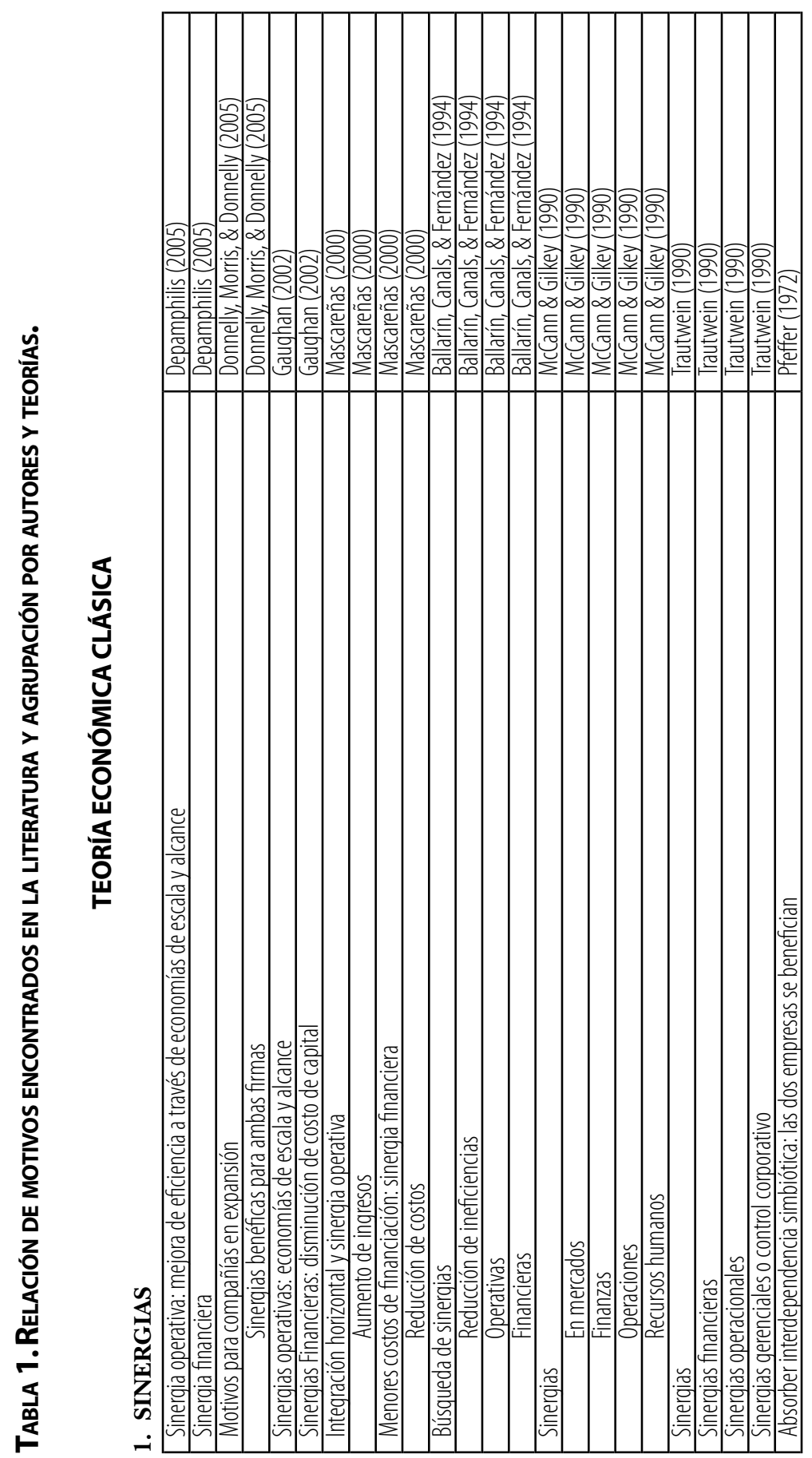




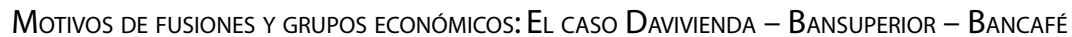
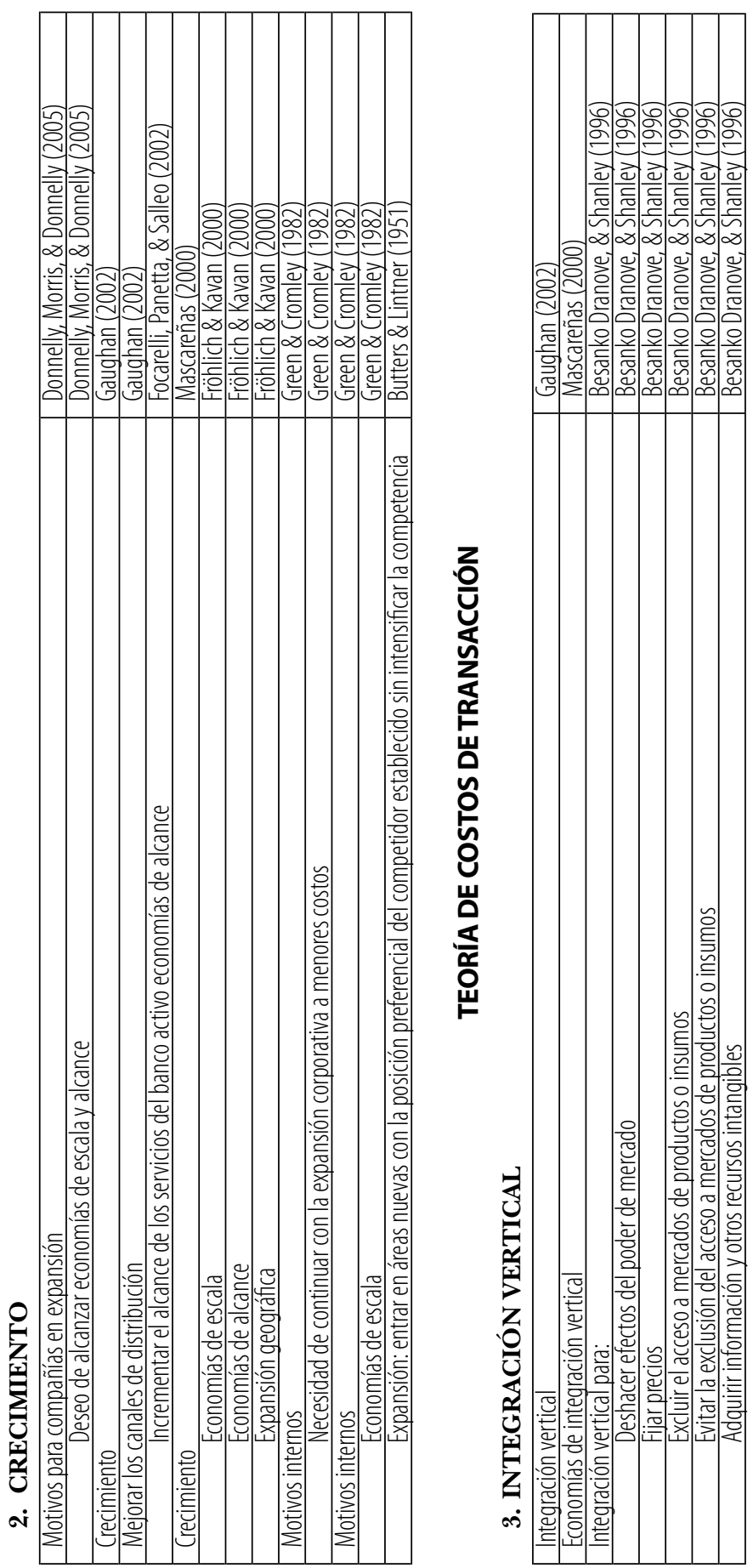
Ingrid SuÁRez / YuRI GorbanefF / JoRge Beltrán
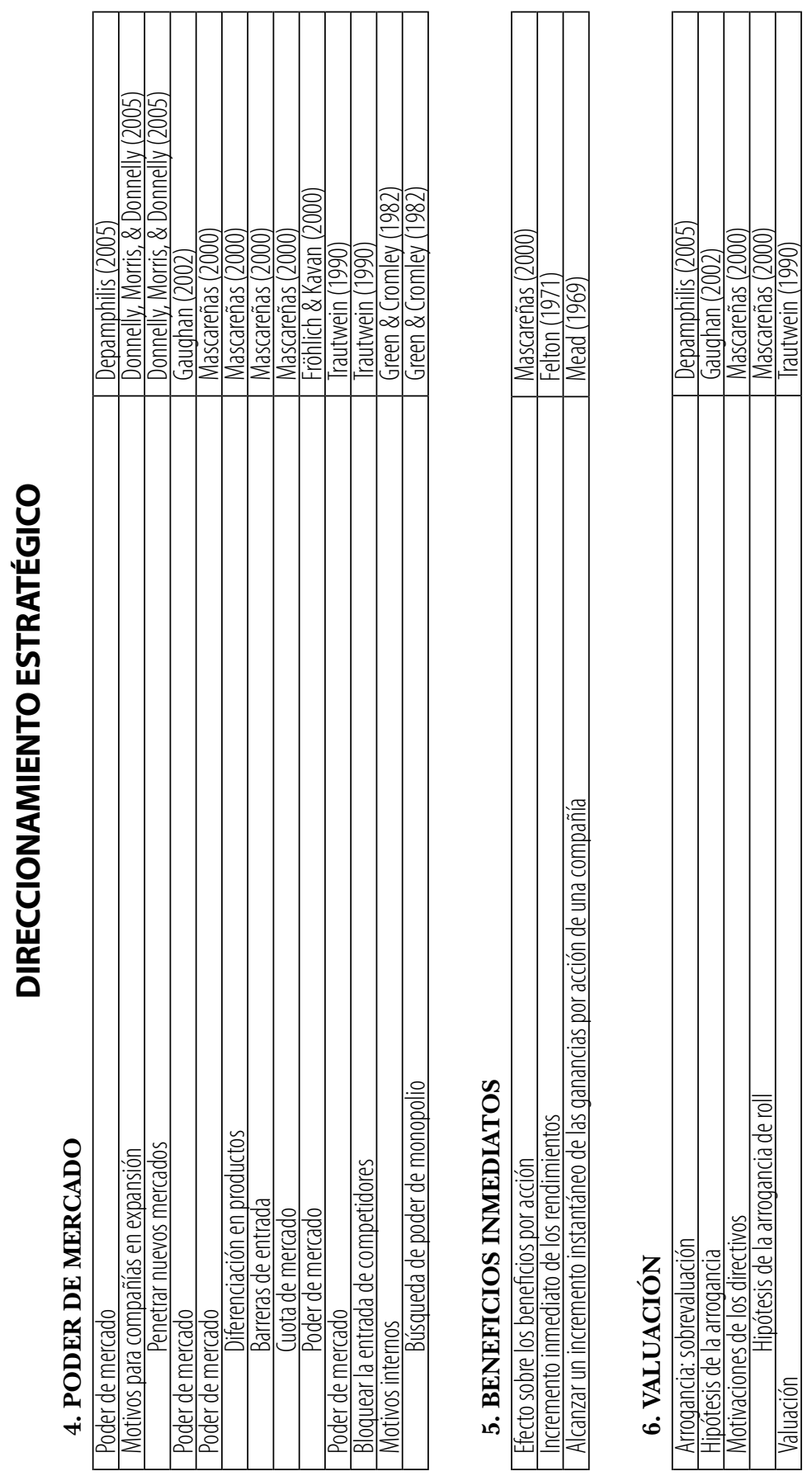
Motivos de fusiones y GRUPOS ECONÓmicos: El CASO DAVIVIENDA - BANSUPERIOR - BanCAFÉ
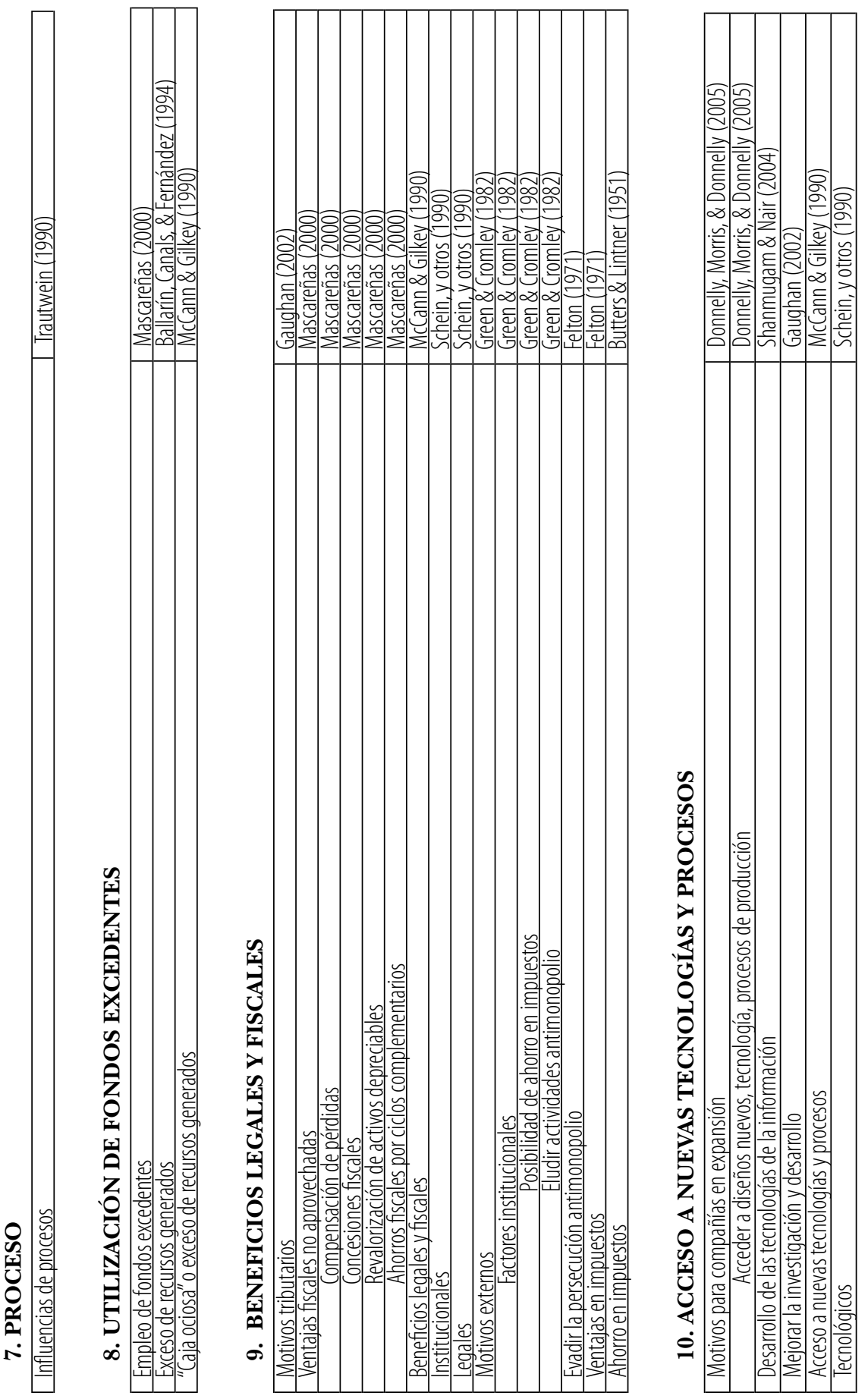
Ingrid SuÁrez / Yuri Gorbaneff / Jorge Beltrán
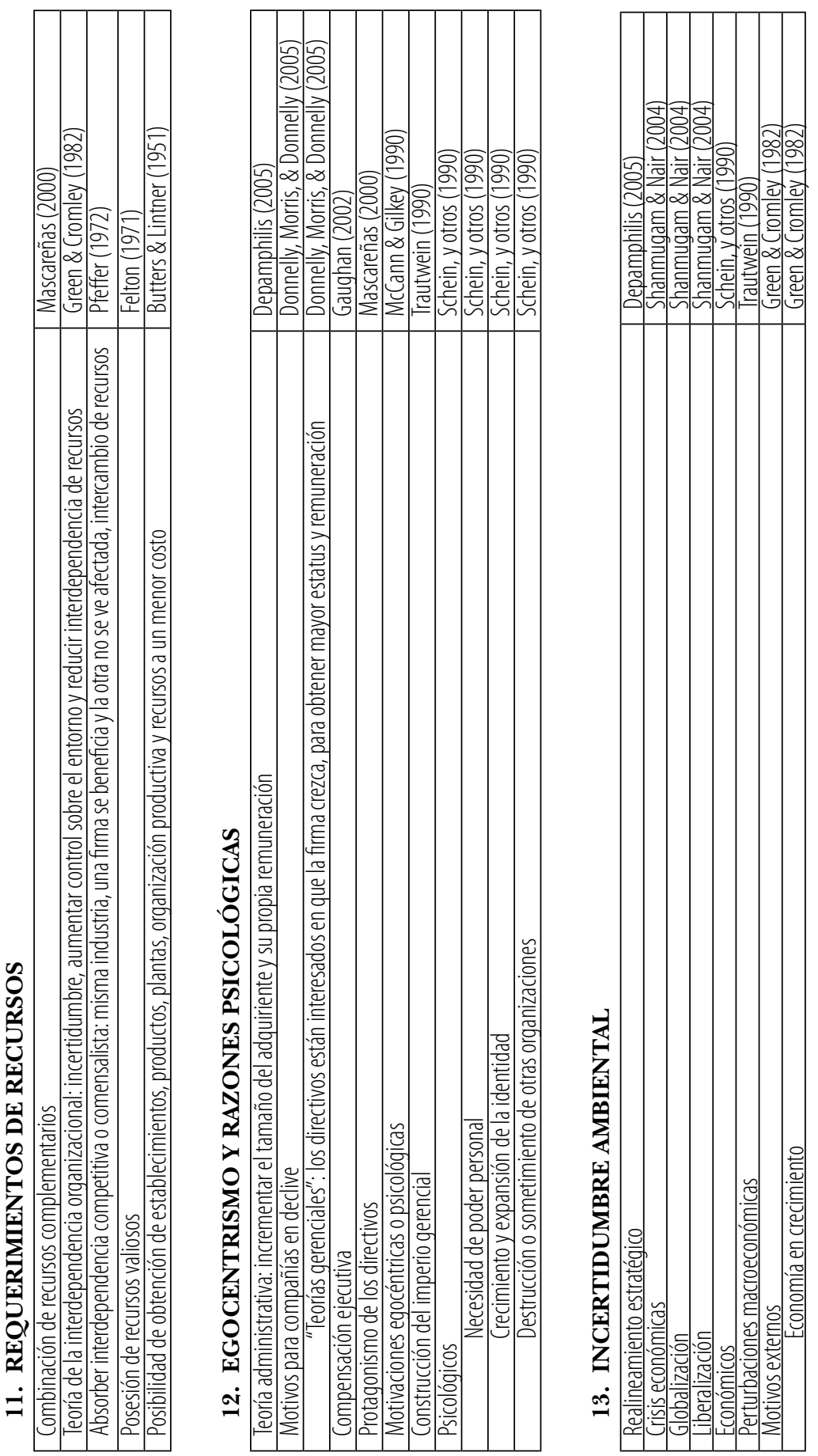
Motivos de fusiones y GRUPOS ECONÓmicos: El CASO DAVIVIENDA - BANSUPERIOR - BANCAFÉ
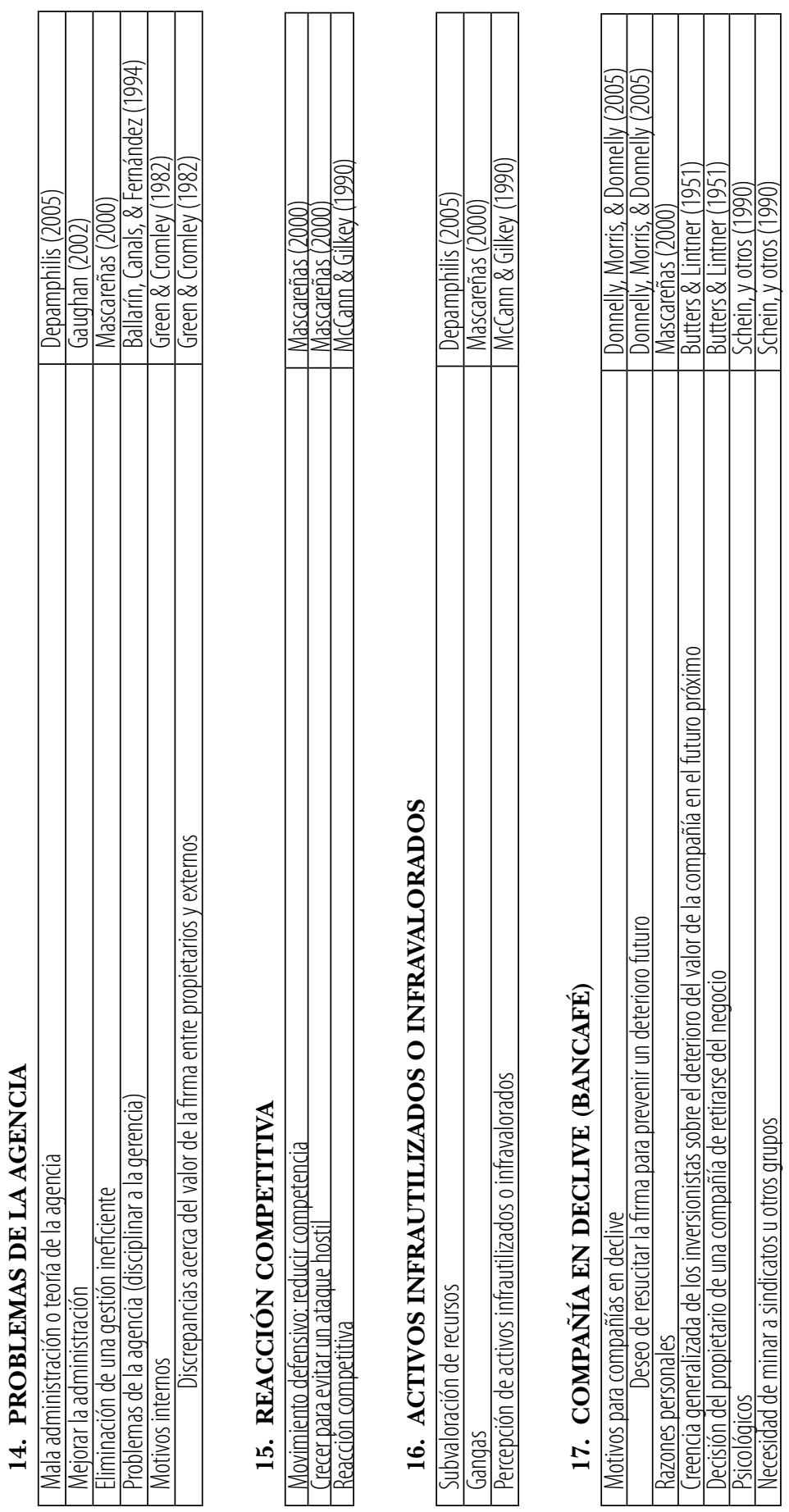
Ingrid SuÁrez / Yuri Gorbaneff / Jorge Beltrán

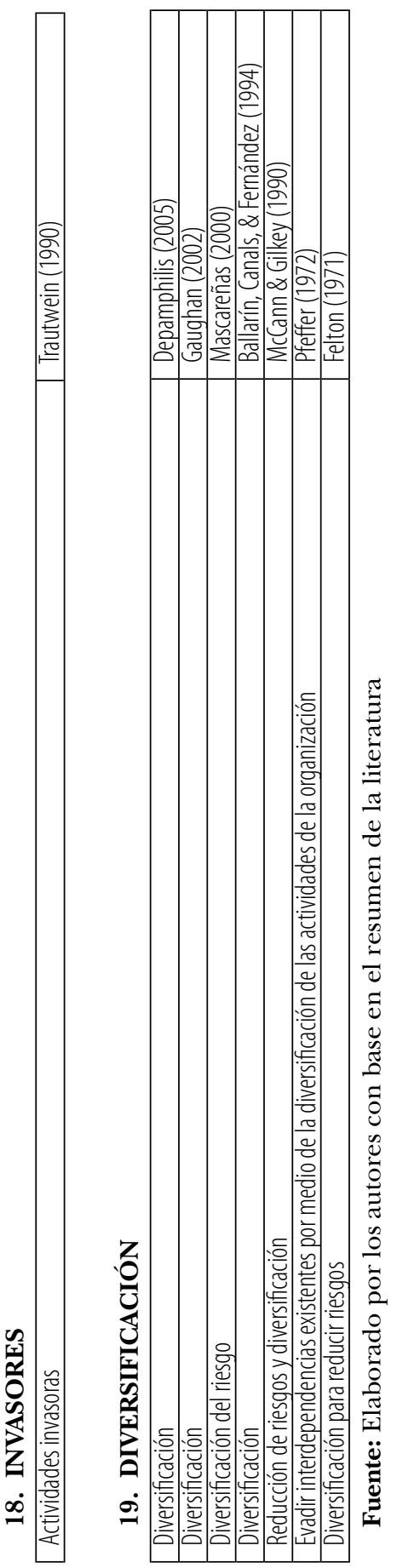




\section{Metodología}

El trabajo es de tipo descriptivo y analítico que utiliza la técnica de investigación documental y el estudio de caso.

Después de revisar los motivos de fusiones descritos en la literatura, se realizó una agrupación de los mismos en diecinueve motivos básicos que sintetizan los motivos estudiados. Los motivos, a su vez, fueron clasificados de acuerdo a las teorías propuestas en principio (ver Tabla1). En primer lugar, se encuentran los motivos que se relacionan con la teoría económica clásica, puesto que permiten disminuir costos de producción, a través de economías de escala y alcance. Entre estos motivos se sitúan los que tienen que ver con sinergias -motivo más nombrado en la literatura- y crecimiento o expansión. El precio de un bien o servicio que sale al mercado, no sólo depende de los costos de producción asociados a él, sino de la suma de éstos con los costos de transacción. En este aspecto, las fusiones pueden realizarse, en segundo lugar, para disminuir los costos de transacción.

Por último, las consideraciones estratégicas incluyen aquellos motivos relacionados con las directrices estratégicas que se plantea la empresa. Estos motivos fueron agrupados en: búsqueda de poder de mercado, obtención de beneficios inmediatos, valuación de la firma objetivo, influencias de procesos administrativos, utilización de fondos excedentes, beneficios legales y fiscales, acceso a nuevas tecnologías y procesos, requerimientos de recursos, egocentrismo y razones psicológicas, incertidumbre ambiental, problemas de la agencia, reacción competitiva, activos infrautilizados o infravalorados, compañía en declive, actividades invasoras y diversificación.

La agrupación de los motivos según el enfoque teórico permitió eliminar la duplicación de algunos motivos y reducir el número total de motivos. Esto, en su turno, permitió dar un orden lógico a la guía de la entrevista que fue diseñada.

El estudio de caso permite investigar un fenómeno contemporáneo en su contexto real (Yin, 2003, pp.13-14). Para este estudio de caso se siguieron los componentes básicos para su diseño propuestos por Yin (2003, p. 21), que incluye (a) preguntas de estudio, (b) proposiciones de estudio, (c) unidades de análisis, (d) conexión lógica 
de los datos con las proposiciones y (e) criterio de interpretación de hallazgos. Este método ofrece explicaciones causales, que permiten comprender las relaciones complejas que la experiencia transmite (Stake, 1998, p. 42).

Las entrevistas fueron concedidas por el vicepresidente jurídico de Davivienda; el director de la Regional Bogotá de Promociones y Cobranzas Beta S.A., compañía que forma parte de las Sociedades Bolívar, y el director financiero y administrativo de Promociones y Cobranzas Beta S.A., encargado de dirigir un comité en la fusión de Davivienda - Bansuperior. Los tres empleados fueron testigos y participantes en el proceso de la fusión.

Cada motivo de la fusión fue discutido con los entrevistados y evaluado por ellos, en una escala de Likert. Esto permitió, a los investigadores, registrar el peso de cada motivo en la decisión de la fusión, como lo percibieron los entrevistados (Malhotra y Peterson, 2006, pp. 264-265; Glaister y Buckley, 1996, p. 312). También se realizaron preguntas abiertas que pretendían ahondar en los motivos y el comportamiento de los actores durante y después de la fusión.

Finalmente, se realizó el análisis cualitativo y cuantitativo de la información recolectada. Se estimó el Alpha de Cronbach con SPSS, para el formato de entrevista de escala de Likert, con el fin de analizar la confiabilidad y consistencia interna de la prueba (Ledesma, Molina, y Varelo, 2002, p. 143; Gliem, J., y Gliem, R., 2003, pp. 82-87). El resultado que arrojó la prueba para los 35 ítems, fue un Alpha de Cronbach de 0,787, valor que permite aceptar la prueba.

\section{DaVivienda - Bansuperior - Bancafe}

La Corporación Colombiana de Ahorro y Vivienda Davivienda, fundada en 1972, pertenece a uno de los grupos empresariales más grandes del país: el Grupo Empresarial Bolívar. Es una entidad de intermediación y servicios financieros, creada para promover el ahorro y la financiación de vivienda.

Bansuperior es un banco privado, creado para proveer servicios financieros, especializado en la tarjeta de crédito Diners. Bancafé es un banco estatal, establecido en 1978 con el fin de proveer servicios financieros para promover el desarrollo del sector cafetero. 


\section{Estudio de Caso Davivienda -Bansuperior - Bancafé}

Los motivos de la fusión con Bansuperior en septiembre de 2005, fueron la búsqueda de posicionamiento, acceso a mayor cuota de mercado, capacidades y recursos. Bansuperior poseía la franquicia de la tarjeta de crédito Diners para Colombia. Davivienda advirtió que obtenía, en menor tiempo y a menores costos, el acceso a un millón de usuarios de la tarjeta Diners. Bansuperior se encontraba en un buen momento antes de la fusión. La tarjeta de crédito Diners estaba posicionada como un producto diferenciado que se destacaba por la superioridad en el servicio al cliente. Davivienda incorporó en su totalidad y sin modificaciones el concepto de negocios de Diners. Sin embargo, el impacto de la fusión fue significativo y generó problemas a la hora de la integración de los sistemas de información. Como consecuencia, algunos clientes no se adaptaron al cambio y cancelaron sus tarjetas Diners.

Junto con Banco Superior, el Grupo Bolívar adquirió Ediciones Gama y Cobranzas Beta. Ediciones Gama era la encargada de editar y publicar la revista Diners, vehículo de comunicación con los usuarios de la tarjeta y un instrumento de su diferenciación. Cobranzas Beta, una de las empresas de cobranzas más grande del país, se convirtió, para Davivienda, en un importante proveedor de servicios por cuanto el mayor activo de un banco es su cartera de créditos, mientras su pasivo lo constituyen los depósitos de los clientes. Con la fusión, el número de los clientes de Cobranzas Beta pasó de 1 millón a 7 millones, y el número de empleados, de 150 a 700.

No obstante, Davivienda no aprovechó todos los conocimientos de Bansuperior, situación que le valió de experiencia para su siguiente fusión, un año más tarde, el 12 de Octubre de 2006, cuando Davivienda ganó la subasta pública del 99,06\% de las acciones del banco estatal Bancafé, por 2 .21 billones de pesos (La República, 2006c; Revista Dinero, 2007). Para esta nueva fusión, Davivienda contaba con la experiencia y se disponía a adquirir los conocimientos relacionados con créditos a microempresas, banca comercial en general y créditos para entidades oficiales. La fortaleza de Davivienda era la banca de consumo. Los empleados de Davivienda no estaban acostumbrados a prestar grandes cantidades de dinero a entidades 
oficiales bajo la promesa de futuros ingresos tributarios o de lotería. Tampoco sabían evaluar el riesgo de los préstamos comerciales que desembolsan grandes cantidades de dinero a un solo cliente.

La experiencia de Bancafé en la banca corporativa, cafetera e internacional, sumada a la tradición de Davivienda en banca personal, se percibía por los estrategas de Davivienda como una fuente de sinergias. Efectivamente, se obtuvieron las sinergias financieras que se reflejan en las calificaciones de riesgo otorgadas a Davivienda tras la fusión, entre las que se encuentran las de Duff \& Phelps Colombia y BRC Investor Services, quienes calificaron al nuevo banco con el más alto nivel, AAA (triple A) para deuda de largo plazo y nivel alto (DP1+ y BRC 1+) para deuda a corto plazo (BRC Investor Services S.A., 22 de Febrero de 2008).

Otros tipos de sinergias, como las operativas, gerenciales y de recursos humanos, tuvieron lugar de distintas formas. La ampliación del portafolio de productos con servicios complementarios, generó economías de escala y sinergias operativas puesto que el nuevo banco puede ofrecer una mayor cantidad de productos y servicios a sus clientes antiguos y nuevos.

Las sinergias gerenciales y en recursos humanos, se lograron a través del traslado de know - how de los trabajadores y gerentes de Bancafé, que debían transmitir toda su experiencia y conocimientos a Davivienda a menores costos y con menor probabilidad de error.

Por otra parte, el incremento en el volumen de operaciones (de dos y medio millones de clientes pasó a cuatro millones), permitió aprovechar el personal de manera más intensiva, automatizar sus operaciones, profundizar la división del trabajo y ahorrar en costos de insumos, lo que al final se traduce en una reducción de los costos de operación. Actualmente, algunos insumos de oficina son menos costosos, dado que se solicitan en mayores cantidades.

Los estrategas de Davivienda no esperaban aprender una nueva tecnología de información de los bancos adquiridos. Previsiblemente, la integración de los sistemas de información acarreó las fricciones en diversos aspectos de las operaciones. El sistema de información de Davivienda es nuevo, mientras que el sistema Bankvision de Bancafé era costoso, inseguro y desactualizado. Esta situación no se presentó en la fusión con Bansuperior, cuyo sistema de información 
era actualizado. Sin embargo, la integración de las plataformas de Davivienda y Bansuperior también presentó algunos traumatismos que van a demorar 2 - 3 años en solucionarse, según los entrevistados.

Uno de los motivos de Davivienda era lograr economías de escala y una mayor división del trabajo. Después de la fusión, 2 personas hacen lo que antes hacían 3, por lo cual se reducen costos y se incrementa la eficiencia. Si bien los clientes de Bancafé pasaron a Davivienda, solo los empleados clave del personal de Bancafé fueron invitados a unirse al nuevo banco. Lo anterior se debió a una mayor carga laboral y a la automatización de distintas operaciones que, en su turno, se hizo posible gracias al aumento del volumen de las operaciones en Davivienda post fusión.

Los artífices de la fusión no tenían en mente aprender las nuevas tecnologías de Bancafé ni de Bansuperior. Bancafé tenía un sindicato que obstaculizaba la automatización de las operaciones. Algunas actividades como contar dinero y enviar cheques entre otras, se realizaban de manera manual, lo que generaba mayores costos de operación. De aquí, el brusco cambio al que se vieron sometidos los empleados de Bancafé, siendo obligados a entender y usar un nuevo sistema, al tiempo, que asumir varias tareas, es decir, mayor cantidad de trabajo.

Los entrevistados estaban de acuerdo en que Davivienda tuvo como motivos estratégicos, la búsqueda de poder de mercado en sus tres formas: diferenciación en producto, barreras a la entrada y ampliación de cuota de mercado. La búsqueda del poder de mercado fue prioridad, para Davivienda, debido a la tendencia de reducción del número de bancos colombianos y al aumento de rivalidad entre ellos. Por medio de las fusiones y quiebras, en los últimos 10 años, el número de bancos en Colombia se redujo de más de 30 a 16. Para enfrentar la rivalidad y disuadir a los nuevos entrantes, entre ellos, grandes bancos extranjeros como HSBC y General Electric Money, Davivienda optó por aumentar su poder de mercado a través de la fusión.

Uno de los objetivos de Davivienda fue lograr sinergias operativas basadas en economías de alcance. Bancafé, cuya fortaleza era el crédito comercial, y Bansuperior, cuya fortaleza fue la franquicia Diners, eran competidores directos de Davivienda, especializada en 
el crédito de consumo e hipotecario. Después de la fusión, Bancafé y Bansuperior se convirtieron en un complemento estratégico. Concretamente, si antes de la fusión, un cliente de Davivienda tenía en promedio 2.5 productos con el Banco, después de la fusión, se espera, este indicador crezca a 7 productos por cliente en promedio

Davivienda no tenía una intención estratégica definida en cuanto al uso de la marca de Bancafé. Uno de los entrevistados expresó que Davivienda estaba interesada en conservar y utilizar esta marca que tiene reconocimiento en el mercado nacional y en el exterior, particularmente en Miami y Panamá. Pero otros entrevistados señalaron que tal motivación no existía y que la marca de Bancafé estaba ya deteriorada debido a su bajo nivel de servicio al cliente, lentitud en su capacidad de respuesta y tecnología de información atrasada, por lo cual no significaba un interés para Davivienda

La expectativa de Davivienda de mejorar su posicionamiento estratégico se justificó porque su precio por acción repuntó inmediatamente se conoció la noticia de la adquisición de Bancafé, y, posteriormente, mejoraron las utilidades de Davivienda.

Por el contrario, el motivo de información privilegiada fue rechazado, dado que, en Colombia, el principio de igualdad de información prima en estas operaciones, y se garantiza por medio del pliego exactamente igual para todos los participantes que entrarán a la venta.

Los motivos estratégicos fueron vistos por todos los entrevistados como los de mayor peso para los estrategas de Davivienda. Los motivos estratégicos se desprenden del mapa estratégico fijado en 2004 por el Banco, en el cual se esbozan objetivos primordiales que pueden obtenerse con una fusión, como es la creación de valor para el accionista, a través de mayor eficiencia, menores riesgos por la diversificación y mayores rentabilidades con base en una mayor presencia en el mercado.

Los entrevistados asignaron un peso moderado al motivo de la reducción del riesgo. Parece que, para Davivienda, el aumento de la cantidad de los clientes en la banca de consumo permitía diversificar el riesgo, pero este motivo no era comparable, por su peso, con los motivos del posicionamiento y la competitividad.

El motivo de reducir la incertidumbre ambiental desempeñó un papel importante en la decisión de la fusión. En Colombia se cree 
que los grandes bancos internacionales, como General Electric o HSBC, van a reforzar su presencia en el país, por lo cual un mayor control de los recursos a través de la fusión emerge como una estrategia atractiva. El motivo de incertidumbre ambiental fue aceptado por los entrevistados, y al respecto, es importante añadir que en Colombia, las oleadas de fusiones han sucedido a crisis financieras. La crisis financiera de 1998-1999, ocasionó 89 liquidaciones en todo el sector financiero, y a partir del 2003, se viene gestando un proceso de recuperación a partir de fusiones bancarias, según el informe de Junio de 2006 de la Asociación Nacional de Instituciones Financieras (ANIF, 2006).

Para Davivienda, el motivo de exceso de recursos en la caja no fue visto como válido por los entrevistados porque Davivienda no tenía el dinero para hacer la adquisición y tuvo que recurrir a nuevos aportes de los socios y a préstamos internacionales (US\$240 millones de la Corporación Financiera Internacional, entidad adscrita al Banco Mundial) para cubrir el monto total.

Los beneficios legales y fiscales, no tuvieron ningún peso en la decisión de Davivienda.

En cuanto a los motivos inspirados en el enfoque de recursos y capacidades, su peso fue importante a la hora de tomar la decisión sobre realizar la fusión. Davivienda aspiraba a obtener el acceso a los recursos físicos, a los clientes y a las capacidades humanas, aunque, ciertamente no a las tecnologías de Bansuperior y mucho menos de Bancafé. Sus aspiraciones se realizaron dado que Davivienda se convirtió en la tercera institución financiera más grande en Colombia con activos por US $\$ 8.06$ billones, depósitos por US $\$ 6.02$ billones y una cartera de US $\$ 4.9$ billones a diciembre 31 de 2006 . Tras la fusión, Davivienda dispone de 540 oficinas, alrededor de 4 millones de clientes y 1200 cajeros automáticos. De estos recursos, Bancafé aportó 237 oficinas, un millón y medio de clientes y 431 cajeros automáticos.

Davivienda vivió un interesante proceso e aprendizaje en cuanto a la adquisición de las capacidades humanas. Este motivo figura como poco relevante en el episodio de la fusión con Bansuperior. En esta ocasión, los dirigentes de Davivienda creían que era suficiente invitar a algunos gerentes de Bansuperior a unirse a Davivienda para 
garantizar el aprendizaje de ciertos elementos que los empleados de Bansuperior podían enseñar a los de Davivienda. La realidad resultó ser más compleja. Como rápidamente se dio cuenta Davivienda, además del conocimiento explícito, existe el tácito, el cual es difícil de transmitir. El servicio al cliente, que representaba la fortaleza de Bansuperior, resultó ser la primera víctima. La gerencia de Davivienda tuvo que revertir su política y buscar a ex empleados de Bansuperior para invitarlos a Davivienda, pero el daño a la imagen de la tarjeta Diners ya había sido causado. A la luz de lo ocurrido, la gerencia de Davivienda cambió su política, y, en el episodio de Bancafé, amplió su oferta de empleos para los ex funcionarios de Bancafé, por un lado, y aplicó el método de las mejores prácticas, por el otro. La fórmula de las mejores prácticas consiste en la evaluación de los procedimientos de cada empresa por separado y la posterior elección del más eficaz entre ellos, el cual sería utilizado en Davivienda post fusión.

Los entrevistados fueron unánimes en conceder un peso importante a los motivos de minimizar los costos de transacción. Se trata de los roles que juegan, dentro del grupo Bolívar, la Aseguradora Bolívar, la Capitalizadora Bolívar, las compañías de cobranzas Beta y Libertador y la compañía de software Soft Bolívar. La aseguradora Bolívar vende los seguros de crédito a los clientes de Davivienda. Cuando Davivienda, como consecuencia de la fusión, aumenta el número de sus clientes, automáticamente se aumenta el número de los seguros que vende la Aseguradora Bolívar.

La Capitalizadora Bolívar vende sus servicios (títulos de capitalización) a través de las oficinas de Davivienda; de manera que si existe un mayor número de oficinas y el acceso a un mayor número de los clientes, la Capitalizadora ahorra los costos de transacción.

Incluso Soft Bolívar que desarrolla y vende sistemas de información para el manejo de recursos humanos y para la integración de los procesos de negocios de pequeñas y medianas empresas, resultó beneficiado con la fusión de Davivienda porque, ahora, pueden ofrecer sus servicios a clientes corporativos y a todos los cafeteros que pasaron a ser clientes de Davivienda.

Cobranzas Libertador que, encontrándose en el grupo Bolívar, vendía servicios jurídicos a Davivienda, ahora se beneficia con la fusión porque amplió, sin costo, el número de sus clientes. 
Davivienda se beneficia con la adquisición de Cobranzas Beta, que se especializa en el cobro de créditos de consumo, hipotecarios y de vehículos, porque los servicios que Davivienda antes tenía que contratar con terceros, ahora se encuentran dentro del mismo grupo Bolívar, lo que permite reducir costos de transacción.

La empresa Soluciones Bolívar también se beneficia de la fusión, puesto que los servicios de plataformas tecnológicas para implementación de SAP y automatización de procesos de negocios, tienen en los nuevos clientes empresariales, compradores potenciales.

Cabe resaltar que, a lo largo del proceso de fusión, e incluso en la post-fusión, han sido evidenciados problemas de compatibilidad de las culturas organizacionales entre las organizaciones fusionadas. Dos años después de la fusión, todavía se habla de rojos, azules y del color café para diferenciar a los que provienen de Davivienda, Bansuperior y Bancafé respectivamente.

Los motivos egocéntricos de construcción del imperio por el gerente no fueron validados por los entrevistados. El gestor de la fusión fue el presidente de Davivienda, quien tuvo en cuenta el plan estratégico, vigente desde el año 2004, para llevar a cabo esta operación. No existieron diferencias marcadas en los objetivos que persiguen los accionistas y los directivos, lo cual se confirma con el apoyo de los accionistas mayoritarios del grupo Bolívar para la operación de la fusión.

\section{Discusión Y CONCLUSIONES}

El análisis de los motivos (Tabla 1) muestra que los autores dan diferentes nombres a los mismos motivos. El grado de detalle es variado. Para formular sus tipologías de motivos, unos autores se basan en los estudios de caso, otros, en las muestras empíricas. Los autores reseñados no son explícitos en cuanto a los fundamentos teóricos sobre las que construyen sus tipologías.

En el caso de Davivienda, los motivos más contundentes de la fusión fueron las sinergias (presente en 8 tipologías), el crecimiento o expansión (presente en 7 tipologías), el ahorro en costos de transacción a través de la integración vertical (presente en 3 tipologías), el poder de mercado (presente en 7 tipologías), los beneficios 
inmediatos (presente en 3 tipologías), procesos organizacionales (presente en 1 tipología), beneficios legales y fiscales (presente en 7 tipologías), acceso a recursos y capacidades (presente en 5 tipologías), egocentrismo y razones psicológicas (presente en 7 tipologías), incertidumbre ambiental (presente en 5 tipologías) y reacción competitiva (presente en 2 tipologías). Los motivos menos contundentes fueron: la valuación (presente en 4 tipologías), problemas de la agencia (presente en 5 tipologías) y los activos infrautilizados o infravalorados (presente en 3 tipologías). Los motivos que no se encontraron fueron la utilización de fondos excedentes (presente en 3 tipologías) y el acceso a nuevas tecnologías y procesos (presente en 5 tipologías).

En general, las tipologías de motivos estudiadas pueden ser verificadas en el caso de estudio. El motivo más importante de esta fusión fue la reacción a la competencia, debido a la creciente globalización y liberalización del sector bancario colombiano.

El caso Davivienda - Bansuperior -Bancafé sugiere que la fusión tiene un carácter exclusivamente horizontal o vertical, sólo si las organizaciones involucradas actúan de manera independiente. Si una de las organizaciones involucradas pertenece a un grupo económico o posee relaciones de alianza patrimonial con otras organizaciones, la fusión deja de ser exclusivamente horizontal o vertical y se transforma en vertical y horizontal al mismo tiempo. La fusión Davivienda - Bansuperior -Bancafé es, en un principio, horizontal. A pesar de esto, los arquitectos de la fusión esperaban reducir los costos de transacción en las relaciones entre Davivienda, por un lado, y sus proveedores y clientes, por el otro, es decir, tenían en mente los motivos verticales. Efectivamente, se constató que, a través de Davivienda, otras empresas del Grupo Bolívar se beneficiaron de la fusión realizada por el banco. Por lo tanto, las demás empresas del Grupo Bolívar, pudieron obtener ventajas de la fusión, sin la necesidad de realizar una fusión o adquisición vertical directamente, sino como consecuencia de la fusión horizontal de una empresa parte del grupo, en este caso Davivienda.

Las empresas del Grupo Bolívar (tercer conglomerado financiero de Colombia) que obtuvieron beneficios de la fusión, creando enlaces verticales a través de enlaces horizontales, fueron: Seguros Bolí- 
var, Capitalizadora Bolívar, Empresas de Cobranzas Beta y el Libertador, Soft Bolívar, Soluciones Bolívar y Confinanciera. Estos enlaces verticales se reflejaron en el mayor volumen de operaciones que empezaron a generar estas empresas tras la fusión. En consecuencia, una fusión horizontal de una empresa, que pertenece a un grupo empresarial, permite obtener beneficios a las demás empresas del grupo a través de la disminución de los costos de transacción entre las demás empresas pertenecientes al grupo y la empresa fusionada.

El aporte de este trabajo consiste en evidenciar que entre los motivos de una fusión se mezclan las consideraciones de tipo horizontal y vertical. Esta confluencia de motivos horizontales y verticales no fue estudiada en la literatura. Es un hallazgo novedoso, pues representa una nueva perspectiva en el estudio de las fusiones, dado que existe una confusión teórica de los autores, cuando no identifican el enfoque teórico al que pertenece cada motivo, lo cual puede deberse a la indeterminación de los motivos de carácter vertical y aquellos de carácter horizontal. 


\section{RefERENCIAS}

Asociación Nacional de Instituciones Financieras (ANIF). (Junio de 2006). Fusiones y Adquisiciones en el Sector Financiero Colombiano: Análisis y Propuestas sobre la Consolidación Bancaria (1990-2006). Bogotá.

Ballarín, E., Canals, J., y Fernández, P. (1994). Fusiones y adquisiciones de empresas. Un enfoque integrador. Madrid: Alianza.

Berggrun, L. (2006). La fusión de Bancolombia, Conavi y Corfinsura: una aplicación de la metodología de estudio de eventos. Estudios Gerenciales, 83-102.

Besanko, D., Dranove, D., y Shanley, M. (1996). The Economics of Strategy. New York: John Wiley y Sons, Inc.

BRC Investor Services S.A. (22 de febrero de 2008). Banco Davivienda S.A. Revisión Periódica 2008. Acta No. 77.

Butters, K., y Lintner, J. (1951). Tax and Non-Tax Motivations for Mergers. The Journal of Finance, 6 (4), 361-382.

Coase, R. (1937). The Nature of the Firm. Economica, 4, 386-405.

Daft, R. L. (2000). Teoría y Diseño Organizacional. México: International Thomson Publishing.

Depamphilis, D. (2005). Mergers, Acquisitions, and Other Restructuring Activities (3rd. ed.). Los Angeles: Elsevier Academia Press.

Dinero: Davivienda invertirá 165 millones de dólares en el proceso de fusión con Bancafé. (03 de 09 de 2007). Recuperado el 20 de 03 de 2008, de ADN: http:/ / www.adn.es/dinero/20070903/ NWS-2367-Davivienda-Bancafe-invertira-millones-dolares.html

Donnelly, T., Morris, D., y Donnelly, T. (2005). Renault-Nissan: a marriage of necessity? European Business Review, 17 (5), 428-440.

Felton, J. R. (1971). Conglomerate Mergers, Concentration and Competition. American Journal of Economics and Sociology, 30 (3), 225-242.

Focarelli, D., Panetta, F., y Salleo, C. (2002). Why do banks merge? Journal of Money, Credit and Banking, 34 (4), 1047-1066.

Fröhlich, C., y Kavan, B. (2000). An examination of bank merger activity: a strategic framework content analysis. Academy of Accounting and Financial Studies, 1-5. 
Gaughan, P. A. (2002). Mergers, Acquisitions, and Corporate Restructurings (3rd. ed.). New York: University Edition John Wiley y Sons.

Glaister, K., y Buckley, P. (1996). Strategic Motives for International Alliance Formation. Journal of Management Studies, 33 (3), 301-332.

Gliem, J., y Gliem, R. (2003). Calculating, Interpreting and Reporting Cronbach's Alpha Reliability Coefficient for Likert-Type Scales. Midwest Research-to-Practice Conference in Adult, Continuing, andCommunity Education (págs. 82-87). Columbus: Ohio State University.

Green, M. B., y Cromley, R. G. (1982). The Horizontal Merger: Its Motives and Spatial Employment Impacts. Economic Geography, 58 (4), 358-370.

Jones, G. (2008). Teoría organizacional. México: Pearson Education. La República. (17 de 10 de 2006c). Noticias Financieras: En 18 meses Davivienda realizó compras por $\$ 2,7$ billones. Recuperado el 20 de 03 de 2008, de Acciones de Colombia S.A. Comisionista de Bolsa: http://www.accionesdecolombia.com/acciones/ includes / detalladonotif.jsp?idNoticia $=2402$

Ledesma, R., Molina, G., y Varelo, P. (2002). Análisis de consistencia interna mediante Alpha de Cronbach: un programa basado en gráficos dinámicos. Psico-USF, 7 (2), 143-152.

Malhotra, N., y Peterson, M. (2006). Basic Marketing Research: A Decision-Making Approach. New Jersey: Pearson Education.

Mascareñas, J. (2000). Fusiones y adquisiciones de empresas (Tercera ed.). Madrid: McGraw-Hill.

McCann, J. E., y Gilkey, R. (1990). Fusiones y adquisiciones de empresas. (A. Fernández, Trad.) Madrid: Díaz de Santos.

Mead, W. J. (1969). Instantaneus merger profit as a conglomerate merger motive. Westearn Economic Journal, 295-306.

Pfeffer, J. (1972). Merger as a Response to Organizational Interdependence. Administrative Science Quarterly, 17 (3), 382-394.

Schein, E. H., Salk, J. E., Hunt, J. W., Jemison, D. B., Sitkin, S. B., Magnet, M., y otros. (1990). Fusiones y adquisiciones: aspectos culturales y organizativos. Barcelona: Gestión 2000.

Shanmugam, B., y Nair, M. (2004). Mergers and Acquisitions of Banks in Malaysia. Managerial Finance, 30 (4), 1-18. 
Stake, R. E. (1998). Investigación con estudio de casos. Madrid: Morata, S.L.

Tirole, J. (2002). The Theory of Industrial Organization. Cambridge: The MIT Press.

Trautwein, F. (1990). Merger Motives and Merger Prescriptions. Strategic Management Journal, 11 (4), 283-295.

Urdaneta, J. (Julio de 2008). Locals Join M\&A Wave. LatinFinance.

Wernerfelt, B. (1997). A Resource-Based View of the Firm. En N. J. Foss (Ed.), Resources, firms, and strategies. A reader in the resource-based perspective. (págs. 117-130). Great Britain: Oxford Management Readers.

Williamson, O. E. (1996). Theory of the firm. The modern corporation: origins, evolution, attributes. En A. Sen (Ed.), Industrial Organization (págs. 39-91, 41-69). Delhi: Oxford University Press.

Yin, R. K. (2003). Case Study Research: Design and Methods (Third ed., Vol. V). California: SAGE Publications, Inc. 